\title{
Optimization of quantitative proteomic analysis of clots generated from plasma of patients with venous thromboembolism
}

\author{
Aneta Stachowicz ${ }^{1,3}$, Jakub Siudut ${ }^{2}$, Maciej Suski ${ }^{1}$, Rafał Olszanecki ${ }^{1}$, Ryszard Korbut ${ }^{1}$, Anetta Undas ${ }^{2}$ \\ and Jacek R. Wiśniewski ${ }^{3^{*}}$
}

\begin{abstract}
Background: It is well known that fibrin network binds a large variety of proteins, including inhibitors and activators of fibrinolysis, which may affect clot properties, such as stability and susceptibility to fibrinolysis. Specific plasma clot composition differs between individuals and may change in disease states. However, the plasma clot proteome has not yet been in-depth analyzed, mainly due to technical difficulty related to the presence of a highly abundant protein-fibrinogen and fibrin that forms a plasma clot.

Methods: The aim of our study was to optimize quantitative proteomic analysis of fibrin clots prepared ex vivo from citrated plasma of the peripheral blood drawn from patients with prior venous thromboembolism (VTE). We used a multiple enzyme digestion filter aided sample preparation, a multienzyme digestion (MED) FASP method combined with LC-MS/MS analysis performed on a Proxeon Easy-nLC System coupled to the Q Exactive HF mass spectrometer. We also evaluated the impact of peptide fractionation with pipet-tip strong anion exchange (SAX) method on the obtained results.

Results: Our proteomic approach revealed 476 proteins repeatedly identified in the plasma fibrin clots from patients with VTE including extracellular vesicle-derived proteins, lipoproteins, fibrinolysis inhibitors, and proteins involved in immune responses. The MED FASP method using three different enzymes: LysC, trypsin and chymotrypsin increased the number of identified peptides and proteins and their sequence coverage as compared to a single step digestion. Peptide fractionation with a pipet-tip strong anion exchange (SAX) protocol increased the depth of proteomic analyses, but also extended the time needed for sample analysis with LC-MS/MS.
\end{abstract}

Conclusions: The MED FASP method combined with a label-free quantification is an excellent proteomic approach for the analysis of fibrin clots prepared ex vivo from citrated plasma of patients with prior VTE.

Keywords: Proteomics, Clot, Fibrin, Venous thromboembolism, MED FASP

\section{Background}

Atherothrombotic vascular disease and venous thromboembolism (VTE) represent the leading causes of morbidity and mortality in the Western countries [1]. VTE, which encompasses deep vein thrombosis (DVT) and pulmonary embolism (PE), affects $1-3$ patients per 1000

\footnotetext{
*Correspondence: jwisniew@biochem.mpg.de

${ }^{3}$ Department of Proteomics and Signal Transduction, Max Planck Institute of Biochemistry, Am Klopferspitz 18, Martinsried, 82152 Planegg, Germany Full list of author information is available at the end of the article
}

individuals per year $[2,3]$. The pathogenesis of VTE is complex and multifactorial $[3,4]$. It is the most common clinical manifestation of hypercoagulable states, including inherited (e.g. factor V Leiden, prothrombin G20210A mutation, deficiencies of antithrombin, protein $\mathrm{C}$ and protein $\mathrm{S}$ ) or acquired (e.g. cancer, antiphospholipid syndrome, pregnancy, older age) conditions, which are associated with the higher risk of thrombus formation $[5,6]$.

Growing body of evidence indicates that fibrin clot properties represent a novel risk factor for arterial 
and venous thrombosis, especially in younger patients with events of unknown etiology. Interestingly, the prothrombotic plasma fibrin clot phenotype in patients with venous or arterial thrombosis involves thin, highly-branched fibers, which are resistant to lysis $[7,8]$. Moreover, it is well known that fibrin network binds a large variety of proteins, including fibronectin, thrombospondin, von Willebrand factor, $\alpha_{2}$-antiplasmin and interleukin-1 $[9,10]$. Of note, binding of fibrinolysis inhibitors and activators to the clot structure may affect clot properties, such as stability and susceptibility to fibrinolysis. This specific plasma clot composition differs between individuals and may transiently change in disease states. However, the plasma clot proteome, particularly with prothrombotic phenotype associated with either inherited or acquired conditions, has not yet been in-depth analyzed, mainly due to technical difficulty related to the presence of a highly abundant protein-fibrinogen and fibrin that forms a plasma clot [11]. Fibrinogen is a plasma glycoprotein, which consists of $2 \mathrm{~A} \alpha-, 2 \mathrm{~B} \beta$ - and $2 \gamma$-chains, and it accounts for as much as $75 \%$ of all proteins present in the blood clot [12]. Therefore, the proteomic analysis of plasma clots is challenging and until recently only a few reports have described the clot proteome [11, 13, 14]. Talens et al. using 2D gel electrophoresis combined with LCMS/MS analysis identified 18 different non-covalently bound proteins of fibrin clots generated in vitro from plasma of healthy individuals [14]. In turn, Suski et al. applying shotgun proteomics revealed 62 proteins in fibrin clots prepared ex vivo from plasma of patients with acute myocardial infarction [13].

The filter aided sample preparation (FASP) and the multiple enzyme digestion FASP (MED FASP) are one of the most effective proteomic methods for sample preparation. They are reproducible and have high performance with increased depth of proteomic analysis and sequence coverage [15-17]. Thus, the aim of our study was to apply MED FASP and pipet-tip strong anion exchange (SAX) fractionation combined with LC-MS/MS analysis to optimize quantitative proteomic analysis of fibrin clots prepared ex vivo from citrated plasma of the peripheral blood.

\section{Methods}

\section{Patients}

Citrated plasma was obtained from four ambulatory patients with prior VTE episode. The diagnosis of DVT of the lower or upper limb required a positive finding of color duplex sonography. An iliac/caval DVT was defined as abnormal duplex flow patterns typical of thrombosis or an intraluminal filling defect on contrast computed tomography $(\mathrm{CT})$ or magnetic resonance venography. The diagnosis of PE was based on the presence of typical symptoms and positive results of high resolution spiral CT. The Local Ethical Committee in Krakow approved the study (135/KBL/OIL/2013), and participants provided informed consent in accordance with the Declaration of Helsinki.

Blood samples (9:1 of 3.2\% trisodium citrate) were centrifuged at $2560 \times g$ for 20 min (centrifuge $3 \mathrm{~K} 18$ model, swing-out rotor no. 11133 (Sigma-Aldrich, Germany) at $20^{\circ} \mathrm{C}$ within $30 \mathrm{~min}$ of collection, immediately frozen, and stored in aliquots at $-80^{\circ} \mathrm{C}$ until further use.

\section{Plasma clot preparation and lysis}

A fibrin clot was prepared using an assay by Pieters et al. [18]. Briefly, to $100 \mu \mathrm{L}$ of citrate plasma was added $20 \mathrm{mmol} / \mathrm{L}$ calcium chloride and $1 \mathrm{U} / \mathrm{mL}$ thrombin (Merck, USA). This mixture was placed into plastic tubes, which were placed into a wet chamber. After $120 \mathrm{~min}$ of incubation tubes were connected to a reservoir of a buffer $(0.05 \mathrm{~mol} / \mathrm{L}$ Tris- $\mathrm{HCl}, 0.1 \mathrm{~mol} / \mathrm{L} \mathrm{NaCl}, \mathrm{pH} 7.5)$, which rinsed a fibrin gel for $1 \mathrm{~h}$. The clots were immediately frozen at $-80^{\circ} \mathrm{C}$.

Clots were lysed in a buffer consisting of $0.1 \mathrm{M}$ Tris$\mathrm{HCl}, \mathrm{pH} 8.0,1 \%$ SDS and $50 \mathrm{mM}$ DTT at $96{ }^{\circ} \mathrm{C}$ for $10 \mathrm{~min}$.

\section{Protein and peptide determination}

Total protein concentration in lysates and the peptide contents in the digests (see below) were assayed using a tryptophan fluorescence based WF-assay in a microtiter plate format [19]. For measurements, Corning Costar 96-well black flat bottom polystyrene plates (Sigma-Aldrich, Germany) were used.

\section{Multi-enzyme digestion filter aided sample preparation (MED FASP)}

Sample aliquots containing $70 \mu \mathrm{g}$ of total protein were processed using the MED FASP method [16] with modifications described recently [15]. Briefly, proteins were subsequently cleaved overnight with endoproteinase LysC (Wako, Germany), trypsin (Promega, USA) and chymotrypsin (Roche, Switzerland) for 18,3 and $3 \mathrm{~h}$, respectively. Peptide containing fractions were collected after each digestion step. The enzyme to protein ratio was 1:50. Digestions were carried out in $50 \mathrm{mM}$ Tris$\mathrm{HCl}$ for LysC and trypsin and in $50 \mathrm{mM}$ Tris- $\mathrm{HCl}, \mathrm{pH} 7.8$ and $10 \mathrm{mM} \mathrm{CaCl}_{2}$ for chymotrypsin. All reactions were conducted at $37{ }^{\circ} \mathrm{C}$. Aliquots containing $10 \mu \mathrm{g}$ of total peptides were desalted on $\mathrm{C}_{18}$-StageTips [20] and concentrated to a volume of $\sim 5 \mu \mathrm{L}$ and were stored frozen at $-20{ }^{\circ} \mathrm{C}$ until mass spectrometric analysis. 


\section{Peptide fractionation by SAX}

Peptides were fractionated according to the previously described pipet-tip strong anion exchange (SAX) protocol [21] with minor modifications. Briefly, peptides were loaded into tip columns made by stacking six layers of a3M Empore anion exchange disk (1214-5012, Varian, USA) into a $200 \mu \mathrm{L}$ micropipet tip. For column equilibration and elution of fractions, we used Britton and Robinson universal buffer (BRUB) composed of $20 \mathrm{mM}$ acetic acid, $20 \mathrm{mM}$ phosphoric acid and $20 \mathrm{mM}$ boric acid titrated with $\mathrm{NaOH}$ to the desired $\mathrm{pH}$. In the experiments where LysC was used, peptides were loaded into the pipet-tip column at $\mathrm{pH} 12$ and the three fractions were eluted at $\mathrm{pH} 6$, and 2 . Tryptic peptides were loaded at $\mathrm{pH} 5$ and eluted at $\mathrm{pH} 2$. The flow-through and the fractions were analyzed. The peptides resulting from chymotryptic digestion were analyzed directly by liquid chromatography LC-MS/MS.

\section{Liquid chromatography: tandem mass spectrometry}

Analysis of peptide mixtures was performed using a QExactive HF mass spectrometer (Thermo-Fisher Scientific, USA). Aliquots containing $5 \mu \mathrm{g}$ of total peptides were chromatographed on a $50 \mathrm{~cm}$ column with $75 \mu \mathrm{m}$ inner diameter packed C18material (Dr. Maisch $\mathrm{GmbH}$, Germany). Peptide separation was carried out at $300 \mathrm{~nL} / \mathrm{min}$ for $90 \mathrm{~min}$ using a two-step acetonitrile gradient $5-60 \%$ over the first $75 \mathrm{~min}$ and $60-95 \%$ for the following $15 \mathrm{~min}$. The temperature of the column oven was $60{ }^{\circ} \mathrm{C}$. The mass spectrometer operated in data-dependent mode with survey scans acquired at a resolution of 50000 at m/z 400 (transient time $256 \mathrm{~ms}$ ). Up to the top 15 most abundant isotope patterns with charge $\geq+2$ from the survey scan $(300-1650 \mathrm{~m} / \mathrm{z})$ were selected with an isolation window of $1.6 \mathrm{~m} / \mathrm{z}$ and fragmented by Higher Energy Collisional Dissociation (HCD) with normalized collision energies of 25 . The maximum ion injection times for the survey scan and the MS/MS scans were 20 and $60 \mathrm{~ms}$, respectively. The ion target value for MS1 and MS2 scan modes was set to $3 \times 10^{6}$ and $10^{5}$, respectively. The dynamic exclusion was $25 \mathrm{~s}$ and $10 \mathrm{ppm}$. The mass spectrometry data have been deposited to the ProteomeXchange Consortium via the PRIDE partner repository [22] with the dataset identifier: PXD006814.

\section{Data analysis}

The spectra were searched using MaxQuant software. All raw files were searched together in single MaxQuant run using separate parameter options for MS-files from analyses of LysC, trypsin and chymotrypsin. A maximum of 2 missed cleavages was allowed. Carbamidomethylation of cysteines was set as a fixed modification. The minimum peptide length was specified to be 7 amino acids. The initial maximal mass tolerance in MS mode was set to $7 \mathrm{ppm}$, whereas fragment mass tolerance was set to 20 ppm for HCD data. The "matching between the runs"option was used. The maximum false peptide and protein discovery rate was specified as 0.01 . Protein abundances were calculated using the "Total Protein Approach" (TPA) method [23]. The calculations were performed in Microsoft Excel. The pathway analysis was performed by STRING (version 10) bioinformatic tool (Search Tool for the Retrieval of Interacting Genes/Proteins) to reveal functional interactions between proteins. Results were enriched in GO biological processes and GO cellular components with False Discovery Rate $(\mathrm{FDR})<0.05$.

\section{Statistical analysis}

Data are presented as a mean \pm SEM. The equality of variance and the normality of the data were checked. The nonparametric Kruskal-Wallis test or one-way analysis of variance (ANOVA) with the Tukey's post hoc test were used as appropriate. A value of $p<0.05$ was considered as statistically significant. All analyses were performed using Statistica 10.0 software (StatSoft, Poland).

\section{Results and discussion}

Effective protein extraction and digestion to peptides play a pivotal role in accurate quantitative proteomic analysis. Recently, proteomic reactor type methods, including FASP and MED FASP, have been described. In the FASP/MED FASP methods samples are completely dissolved in sodium dodecyl sulfate (SDS) and consecutively digested with up to three enzymes in an ultrafiltration unit $[16,17]$. Here, we have performed the MED FASP method using three different enzymes: LysC, trypsin and chymotrypsin or peptide fractionation by the SAX protocol to optimize the quantitative proteomic analysis of fibrin clots prepared ex vivo from citrated plasma of the peripheral blood drawn from patients with VTE. Plasma clots of 4 patients ( 1 man and 3 women) with a mean age of 36 years (aged from 30 to 58 years) were studied. There were 2 patients with isolated DVT and 2 with isolated PE. Unprovoked VTE occurred in 2 individuals. Mean time since the VTE event was 12 months.

Firstly, we have evaluated the efficiency of digestion with LysC, trypsin and chymotrypsin. The amount of eluted peptides to total protein amount processed was expressed as a yield (Fig. 1a). The yield of digestion with LysC, trypsin and chymotrypsin was around 50, 20 and $10 \%$, respectively, which gave in a total $80 \%$ yield with MED FASP. The consecutive digestion of plasma fibrin clots with LysC, trypsin and chymotrypsin resulted in the increased number of the identified unique peptides $(2388 \pm 66)$ as compared to a single $(1148 \pm 55)$ (LysC) step digestion. Peptide fractionation with SAX protocol led to the similar number of identified unique peptides 

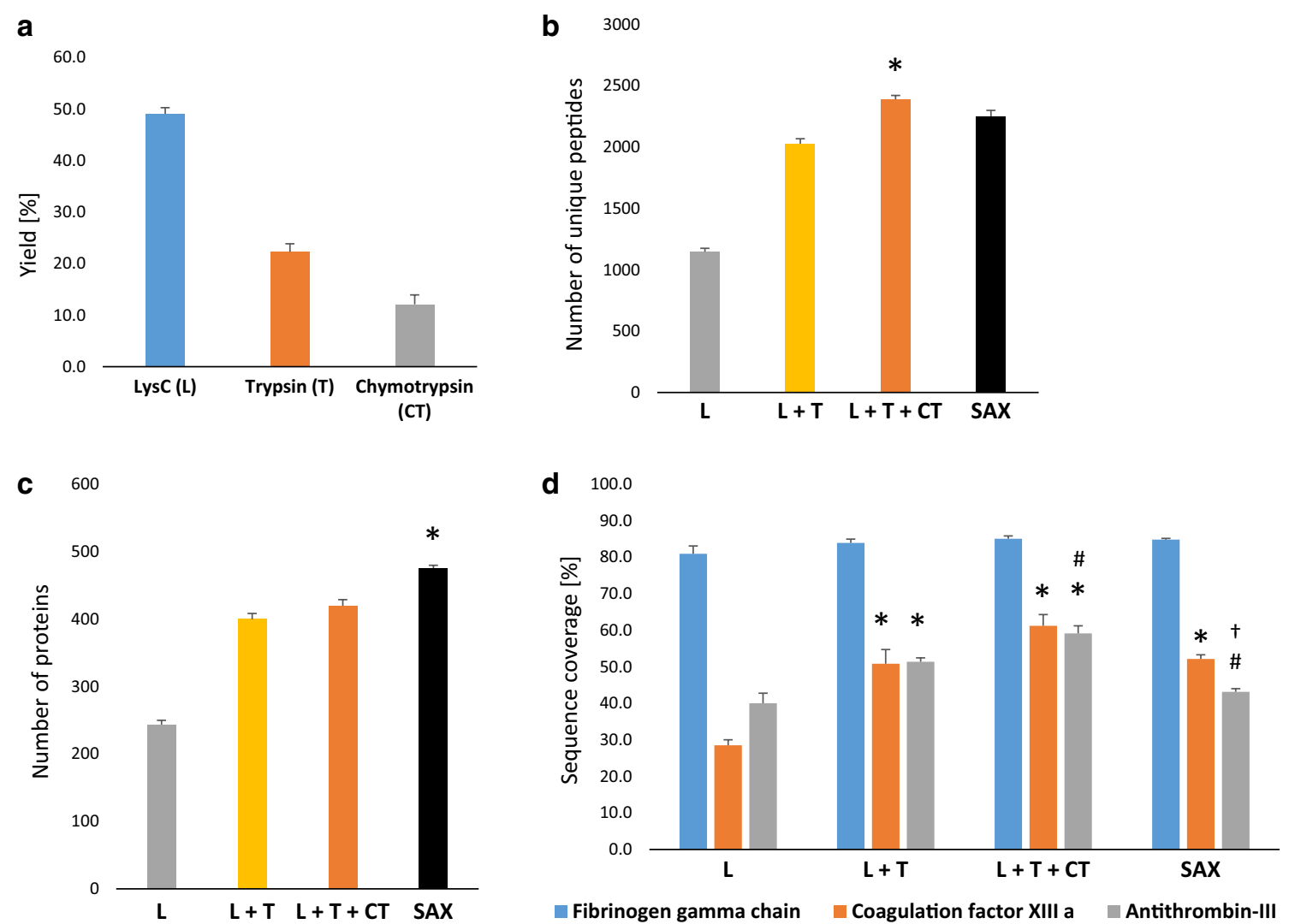

Fig. 1 Efficiency of protein to peptide conversion after digestion with LysC, trypsin and chymotrypsin. The yields were expressed as a ratio of the amount of eluted peptides to total protein amount processed (a). The number of unique peptides identified after sequential digestion with $L y s C$ (L), Lys $C+$ trypsin $(L+T)$, Lys $C$ + trypsin + chymotrypsin $(L+T+C T)$ or peptide fractionation by pipet-tip strong anion exchange (SAX) protocol (b). The number of proteins identified after sequential digestion with $L, L+T, L+T+C T$ or peptide fractionation by SAX (c). Sequence coverage obtained after sequential digestion with $L, L+T, L+T+C T$ or peptide fractionation by $S A X$ for three different proteins: fibrinogen gamma chain, coagulation factor XIII a and antithrombin-III (d). ${ }^{*} p<0.05$ as compared to $L,{ }^{\#} p<0.05$ as compared to $L+T,{ }^{\dagger} p<0.05$ as compared to $L+T+C T$; mean $\pm \mathrm{SEM} ; \mathrm{n}=4$ per group

as obtained by MED FASP with three different enzymes $(2250 \pm 99)$ (Fig. 1b). Moreover, both consecutive digestion with LysC, trypsin and chymotrypsin and SAX fractionation provided the largest number of identified proteins ( $420 \pm 18$ and $476 \pm 8$, respectively) in comparison to a single (LysC) step digestion $(243 \pm 13)$ (Fig. 1c). Of note, SAX approach led to the similar number of identified proteins as compared to MED FASP with three different enzymes, but it also extended the time needed for sample analysis with LC-MS/MS, which is a result of the increased number of runs. Consecutive digestion with LysC, trypsin and chymotrypsin also resulted in a better sequence coverage than a single (LysC) or double (LysC + trypsin) step digestion and SAX fractionation as shown for coagulation factor XIII a, antithrombin-III and fibrinogen gamma chain (Fig. 1d). Interestingly, the differences in sequence coverage between digestion with one, two or three enzymes as well as SAX approach were negligible for most abundant proteins such as fibrinogen gamma chain (Fig. 1d). Noteworthy, our results are consistent with previous one, which have evaluated the MED FASP protocols, and confirm the efficiency of the MED FASP method in proteomic sample preparation $[15,16]$.

Recently, a protein quantification method called Total Protein Approach (TPA) has been described [23]. TPA is applicable to large scale proteomic studies and allows to calculate the protein concentrations without any requirements of spike-in standards or biochemical determination of the sample size. Protein concentrations are directly derived from the MS intensity outputs [24]. Here, we used TPA method to calculate the average concentration of proteins isolated from plasma fibrin clots prepared ex vivo from patients with VTE (Additional file 1: Table 1 and Additional file 2: Table 2). The protein concentrations of some commonly encountered proteins in human plasma fibrin clots measured by MED FASP (LysC + Trypsin + Chymotrypsin) method combined with LC-MS/MS were shown in Table 1. Clearly, the 
most abundant protein in human plasma clots was fibrinogen. Our results indicate that the concentrations of their three chains were almost equal (around $300 \mathrm{nmol} / \mathrm{g}$ ) and were at least 10 times higher than concentrations of other abundant proteins, such as alpha-2-antiplasmin or alpha-2-macroglobulin (Fig. 2a). In turn, coagulation factors, e.g. coagulation factor IX, XII or V were present in human plasma clots at very low concentrations around 1-20 pmol/g (Table 1). Moreover, the depth of our proteomic analysis using MED FASP was around six order of magnitude, which was illustrated by $\log _{10}$ of protein concentrations shown in Fig. 2b. It indicates that MED FASP method combined with a label-free quantification is an excellent proteomic approach for the analysis of fibrin clots prepared ex vivo from plasma of patients with VTE.

We also carried out a bioinformatic analysis of human plasma fibrin clots from patients with VTE, which were measured by MED FASP (LysC + Typsin + Chymotrypsin) method combined with LC-MS/MS. Such an analysis revealed many functional interactions between proteins, which indicates that the most of identified proteins were engaged in common molecular pathways (Fig. 3). To identify these pathways we used STRING (version 10) bioinformatic tool. Among GO biological processes significantly enriched in human plasma clots we revealed molecular pathways, which we were expecting

Table 1 The average concentration of some selected proteins present in human plasma fibrin clots measured by MED FASP (LysC + Typsin + Chymotrypsin) method combined with LC-MS/MS and Total Protein Approach (TPA)

\begin{tabular}{lllc}
\hline Protein IDs & Protein names & Gene names & Average concentration (nmol/g) \\
\hline P08697 & Alpha-2-antiplasmin & SERPINF2 & 39.2436 \\
P01023 & Alpha-2-macroglobulin & A2M & 16.1977 \\
P01008 & Antithrombin-III & SERPINC1 & 1.6678 \\
P02749 & Beta-2-glycoprotein 1 & APOH & 0.1782 \\
P00740 & Coagulation factor IX & F9 & 0.0040 \\
P12259 & Coagulation factor V & F5 & 0.0125 \\
P00451 & Coagulation factor VIII & F8 & 0.0005 \\
P00748 & Coagulation factor XII & F12 & 0.0135 \\
P00488 & Coagulation factor XIII A chain & F13A1 & 13.5540 \\
P05160 & Coagulation factor XIII B chain & F13B & 0.0347 \\
P02671 & Fibrinogen alpha chain & FGA & 303.1711 \\
P02675 & Fibrinogen beta chain & FGB & 377.2742 \\
P02679 & Fibrinogen gamma chain & FGG & 324.3229 \\
P02751 & Fibronectin & FN1 & 62.3088 \\
P00747 & Plasminogen & PLG & 2.8753 \\
P00734 & Prothrombin & F2 & 2.3480 \\
P04004 & Vitronectin & VTN & 1.3471 \\
P04275 & von Willebrand factor & VWF & 0.2985 \\
\hline
\end{tabular}
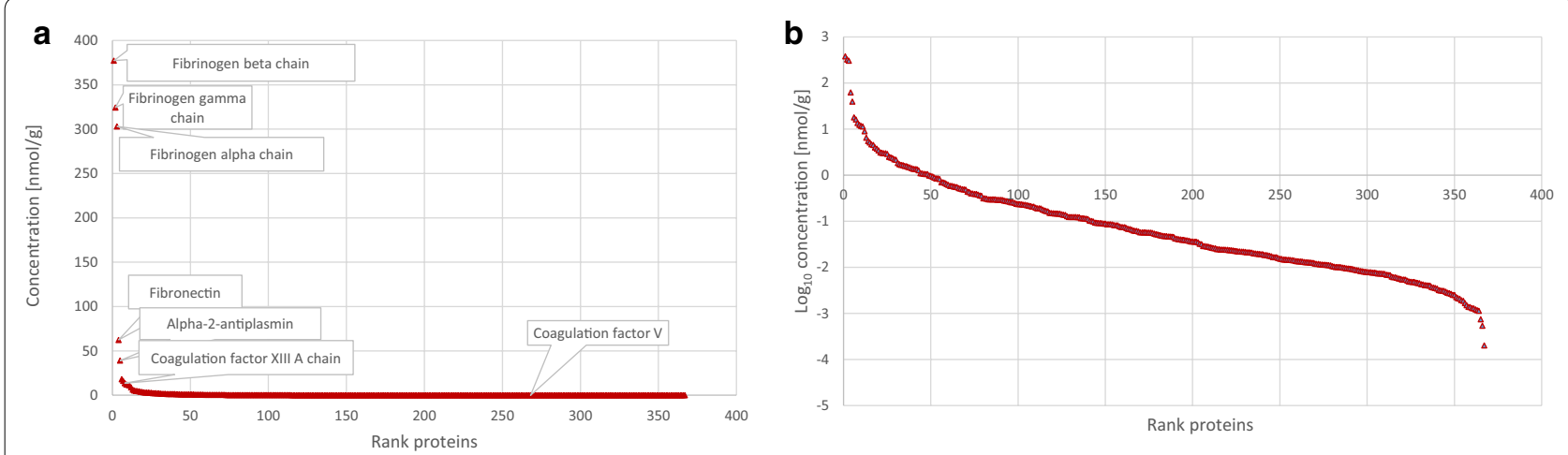

Fig. 2 Concentrations of proteins indentified after sequential digestion with $L y s C+$ trypsin + chymotrypsin $(L+T+C T)$ calculated by Total Protein Approach (TPA) (a). $\log _{10}$ of protein concentrations illustrates the depth of proteomic analysis using MED FASP (b) 

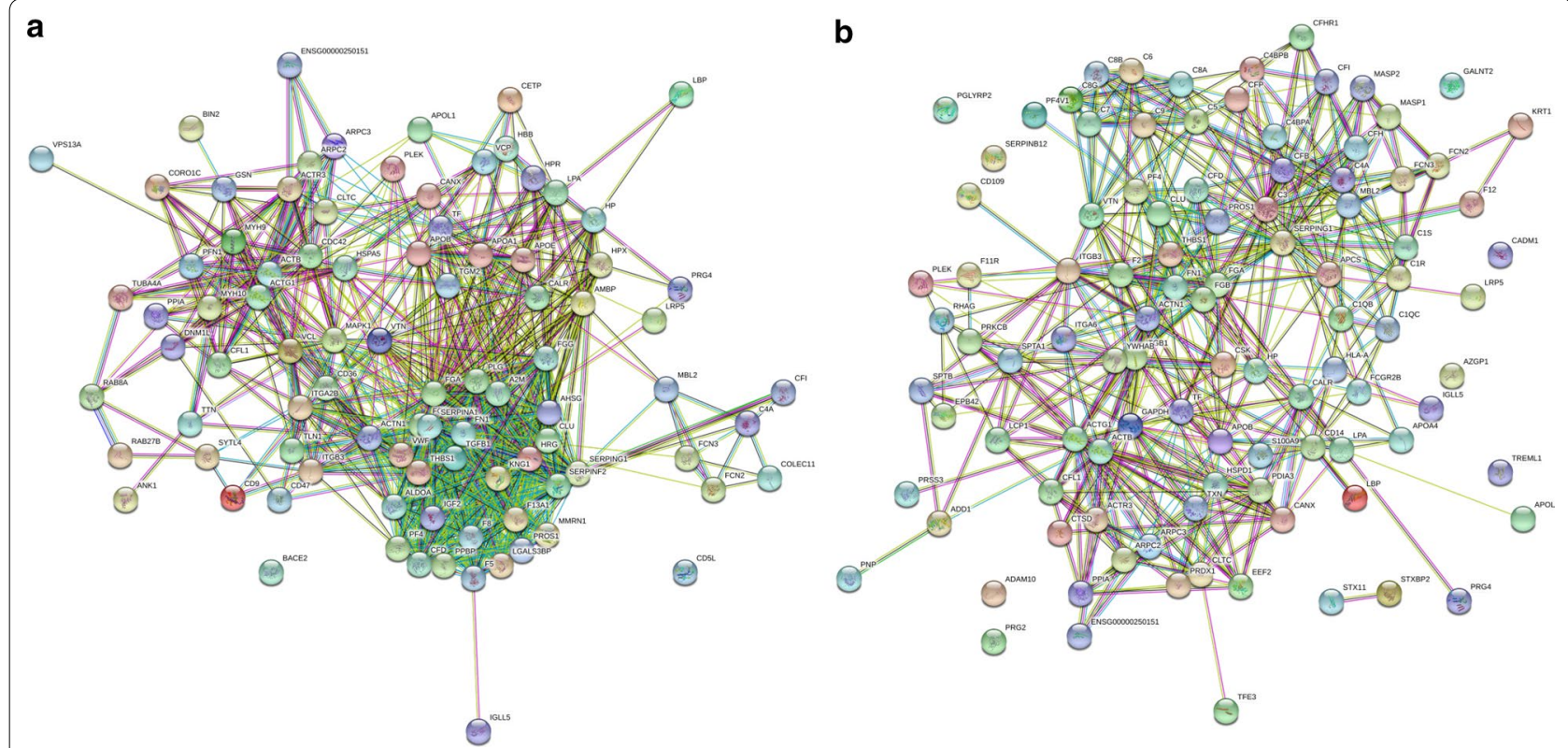

Fig. 3 Bioinformatic analysis by STRING (version 10) of vesicle-mediated transport (a) and immune system (b) proteins identified with MED FASP (LysC + Typsin + Chymotrypsin) method combined with LC-MS/MS reveals functional interactions between proteins. Each node represents a protein and each edge represents an association. Stronger associations are represented by thicker lines

to find, responsible for blood coagulation, platelet activation and degranulation, fibrinolysis, immune system process, regulation of blood coagulation or response to stress (Table 2). Additionally, we performed GO analysis by STRING of cellular components significantly enriched in human plasma clots from patients with VTE. Interestingly, we found that a large number of proteins identified by MED FASP method combined with LC-MS/MS are

Table 2 The selected GO biological processes enriched in human plasma fibrin clots by STRING (version 10) bioinformatic tool

\begin{tabular}{llcc}
\hline Pathway ID & Pathway description & Observed gene count & False discovery rate \\
\hline G0.0072376 & Protein activation cascade & 46 & $4.39 \mathrm{E}-61$ \\
G0.0042060 & Wound healing & 94 & $6.01 \mathrm{E}-53$ \\
G0.0007596 & Blood coagulation & 85 & $1.47 \mathrm{E}-52$ \\
G0.0009611 & Response to wounding & 95 & $1.32 \mathrm{E}-50$ \\
G0.0050878 & Regulation of body fluid levels & 90 & $8.85 \mathrm{E}-50$ \\
G0.0030168 & Platelet activation & 61 & $9.95 \mathrm{E}-50$ \\
G0.0002576 & Platelet degranulation & 43 & $1.88 \mathrm{E}-48$ \\
G0.0065008 & Regulation of biological quality & 167 & $1.44 \mathrm{E}-45$ \\
G0.0006950 & Response to stress & 173 & $8.05 \mathrm{E}-42$ \\
G0.0006956 & Complement activation & 30 & $2.20 \mathrm{E}-39$ \\
G0.0016192 & Vesicle-mediated transport & 91 & $1.54 \mathrm{E}-32$ \\
G0.0001775 & Cell activation & 69 & $5.21 \mathrm{E}-32$ \\
G0.0006887 & Exocytosis & 49 & $1.78 \mathrm{E}-30$ \\
G0.2000257 & Regulation of protein activation cascade & 20 & $8.87 \mathrm{E}-28$ \\
G0.0006959 & Humoral immune response & 33 & $1.54 \mathrm{E}-25$ \\
G0.0002376 & Immune system process & 101 & $1.83 \mathrm{E}-21$ \\
G0.0030193 & Regulation of blood coagulation & 24 & $5.05 \mathrm{E}-20$ \\
G0.0030195 & Negative regulation of blood coagulation & 19 & $4.06 \mathrm{E}-19$ \\
G0.0042730 & Fibrinolysis & 14 & $1.23 \mathrm{E}-17$ \\
\hline
\end{tabular}


Table 3 The selected cellular components (GO term) enriched in human plasma fibrin clots by STRING (version 10) bioinformatic tool

\begin{tabular}{llcc}
\hline Pathway ID & Pathway description & Observed gene count & False discovery rate \\
\hline G0.1903561 & Extracellular vesicle & 270 & $6.40 \mathrm{E}-147$ \\
G0.0070062 & Extracellular exosome & 269 & $1.77 \mathrm{E}-146$ \\
G0.0031988 & Membrane-bounded vesicle & 280 & $1.98 \mathrm{E}-135$ \\
G0.0031982 & Vesicle & 279 & $8.46 \mathrm{E}-131$ \\
G0.0005576 & Extracellular region & 294 & $3.38 \mathrm{E}-123$ \\
G0.0072562 & Blood microparticle & 74 & $4.48 \mathrm{E}-102$ \\
G0.0005615 & Extracellular space & 164 & $3.89 \mathrm{E}-97$ \\
G0.0031091 & Platelet alpha granule & 31 & $1.39 \mathrm{E}-35$ \\
G0.0044433 & Cytoplasmic vesicle part & 54 & $1.81 \mathrm{E}-23$ \\
G0.0043227 & Membrane-bounded organelle & 286 & $3.17 \mathrm{E}-18$ \\
G0.0034358 & Plasma lipoprotein particle & 16 & $1.17 \mathrm{E}-16$ \\
G0.0034364 & High-density lipoprotein particle & 13 & $8.31 \mathrm{E}-15$ \\
G0.0030054 & Cell junction & 63 & $8.70 \mathrm{E}-15$
\end{tabular}

derived from various types of extracellular vesicles (EVs): exosomes, microparticles or membrane-bounded vesicles (Table 3). EVs are released to the extracellular environment by platelets, and to lesser extent by other cells, in particular endothelial cells, monocytes or neutrophils and they facilitate intercellular communication in various processes, e.g. immune response, inflammation or blood coagulation [25]. Importantly, circulating EVs could contribute to increased risk of VTE and arterial thrombosis [26, 27]. Indeed, higher levels of EVs have been observed in carriers of inherited thrombophilic states [28, 29]. The presence of EVs in human plasma fibrin clots derived from patients with VTE could confirm its role in the pathogenesis of thrombosis.

\section{Conclusion}

In this study, we have applied MED FASP and SAX fractionation to optimize quantitative proteomic analysis of fibrin clots prepared ex vivo from citrated plasma of the peripheral blood drawn from patients with prior VTE. Our proteomic approach revealed for the first time 476 proteins repeatedly identified in the plasma fibrin clots from patients with VTE. We observed that MED FASP method using three different enzymes: LysC, trypsin and chymotrypsin increased the number of identified peptides and proteins as well as their sequence coverage as compared to a single step digestion. Peptide fractionation with SAX protocol increased the depth of proteomic analysis, but also extended the time needed for sample analysis with LC-MS/MS. We found that the human plasma fibrin clots from patients with VTE contain extracellular region proteins and extracellular vesicles-derived proteins. Further studies on larger patient groups with different types of VTE are needed to better characterize protein clot composition using proteomic analysis.

In conclusion, the MED FASP method combined with a label-free quantification is an excellent proteomic approach for the analysis of fibrin clots prepared ex vivo from citrated plasma of patients with prior VTE.

\section{Additional files}

Additional file 1: Table 1. The list of proteins identified by MaxQuant software in plasma fibrin clots from patients with VTE, which were measured using MED FASP (LysC + Typsin + Chymotrypsin) method combined with LC-MS/MS and Total Protein Approach (TPA) ( $n=4$ per group)

Additional file 2: Table 2. The list of proteins identified by MaxQuant software in plasma fibrin clots from patients with VTE, which were measured using pipet-tip strong anion exchange (SAX) protocol combined with LC-MS/MS and Total Protein Approach (TPA) ( $n=4$ per group)

\section{Abbreviations}

DVT: deep vein thrombosis; EVs: extracellular vesicles; MED FASP: multiple enzyme digestion filter aided sample preparation; SAX: pipet-tip strong anion exchange; TPA: total protein approach;VTE: venous thromboembolism.

\section{Authors' contributions}

$A U, R O, R K$ and JRW were responsible for the conception and design of the study. AS, JS and MS were responsible for analyses of the samples. AS, MS, JS, $\mathrm{AU}$ and JRW were responsible for the interpretation of the data. AS drafted the article. All authors revised the paper critically for important intellectual content and gave final approval of the version to be published. All authors read and approved the final manuscript.

\section{Author details}

${ }^{1}$ Chair of Pharmacology, Jagiellonian University Medical College, Kraków, Poland. ${ }^{2}$ Institute of Cardiology, Jagiellonian University Medical College, Kraków, Poland. ${ }^{3}$ Department of Proteomics and Signal Transduction, Max Planck Institute of Biochemistry, Am Klopferspitz 18, Martinsried, 82152 Planegg, Germany. 


\section{Acknowledgements}

This work was supported by the Foundation for Polish Science (FNP), Jagiellonian University Medical College_Leading National Research Centre (2012-2017), and German Research Foundation (DFG/Gottfried Wilhelm Leibniz Prize).

\section{Competing interests}

The authors declare that they have no competing interests.

\section{Availability of data and materials}

The mass spectrometry data have been deposited to the ProteomeXchange Consortium via the PRIDE partner repository with the dataset identifier: PXD006814.

\section{Ethics approval and consent to participate}

This study was conducted according to the principles expressed in the Declaration of Helsinki and was approved by the Bioethics Committee (135/KBL/ OIL/2013). All patients gave written informed consent.

\section{Publisher's Note}

Springer Nature remains neutral with regard to jurisdictional claims in published maps and institutional affiliations.

Received: 17 July 2017 Accepted: 18 November 2017

Published online: 28 November 2017

\section{References}

1. Lloyd-Jones DM. Cardiovascular risk prediction: basic concepts, current status, and future directions. Circulation. 2010;121:1768-77.

2. Ahlehoff $\mathrm{O}$, Gislasson GH, Torp-Pedersen C, Hansen PR. Risk assessment for recurrent venous thrombosis. Lancet Lond. Engl. 2011;377:1073

\section{(author reply 1073-1074)}

3. Reitsma PH, Versteeg $\mathrm{HH}$, Middeldorp S. Mechanistic view of risk factors for venous thromboembolism. Arterioscler Thromb Vasc Biol. 2012:32:563-8

4. Lijfering WM, Rosendaal FR, Cannegieter SC. Risk factors for venous thrombosis - current understanding from an epidemiological point of view. Br J Haematol. 2010;149:824-33.

5. Martinelli I, Bucciarelli P, Mannucci PM. Thrombotic risk factors: basic pathophysiology. Crit Care Med. 2010;38:S3-9.

6. Rosendaal FR, Reitsma PH. Genetics of venous thrombosis. J Thromb Haemost JTH. 2009:7(Suppl 1):301-4.

7. Undas A. Fibrin clot properties and their modulation in thrombotic disorders. Thromb Haemost. 2014;112:32-42.

8. Undas A, Ariëns RAS. Fibrin clot structure and function: a role in the pathophysiology of arterial and venous thromboembolic diseases. Arterioscler Thromb Vasc Biol. 2011;31:e88-99.

9. Carr ME. Fibrin formed in plasma is composed of fibers more massive than those formed from purified fibrinogen. Thromb Haemost. 1988;59:535-9.

10. Muszbek L, Bereczky Z, Bagoly Z, Komáromi I, Katona É. Factor XIII: a coagulation factor with multiple plasmatic and cellular functions. Physiol Rev. 2011:91:931-72.

11. Howes J-M, Keen JN, Findlay JB, Carter AM. The application of proteomics technology to thrombosis research: the identification of potential therapeutic targets in cardiovascular disease. Diab Vasc Dis Res. 2008;5:205-12.
12. Burton RA, Tsurupa G, Medved L, Tjandra N. Identification of an ordered compact structure within the recombinant bovine fibrinogen alphaCdomain fragment by NMR. Biochemistry (Mosc.). 2006;45:2257-66.

13. Suski M, Siudut J, Ząbczyk M, Korbut R, Olszanecki R, Undas A. Shotgun analysis of plasma fibrin clot-bound proteins in patients with acute myocardial infarction. Thromb Res. 2015;135:754-9.

14. Talens S, Leebeek FWG, Demmers JAA, Rijken DC. Identification of fibrin clot-bound plasma proteins. PLoS ONE. 2012;7:e41966.

15. Wiśniewski JR. Quantitative evaluation of filter aided sample preparation (FASP) and multienzyme digestion FASP protocols. Anal Chem. 2016:88:5438-43.

16. Wiśniewski JR, Mann M. Consecutive proteolytic digestion in an enzyme reactor increases depth of proteomic and phosphoproteomic analysis. Anal Chem. 2012;84:2631-7.

17. Wiśniewski JR, Zougman A, Nagaraj N, Mann M. Universal sample preparation method for proteome analysis. Nat Methods. 2009:6:359-62.

18. Pieters M, Undas A, Marchi R, De Maat MPM, Weisel JW, Ariëns RAS, et al. An international study on the standardization of fibrin clot permeability measurement: methodological considerations and implications for healthy control values. J Thromb Haemost JTH. 2012;10:2179-81.

19. Wiśniewski JR, Gaugaz FZ. Fast and sensitive total protein and peptide assays for proteomic analysis. Anal Chem. 2015:87:4110-6.

20. Ishihama Y, Rappsilber J, Andersen JS, Mann M. Microcolumns with selfassembled particle frits for proteomics. J Chromatogr A. 2002;979:233-9.

21. Wiśniewski JR, Zougman A, Mann M. Combination of FASP and StageTipbased fractionation allows in-depth analysis of the hippocampal membrane proteome. J Proteome Res. 2009:8:5674-8.

22. Vizcaíno JA, Deutsch EW, Wang R, Csordas A, Reisinger F, Ríos D, et al. ProteomeXchange provides globally coordinated proteomics data submission and dissemination. Nat Biotechnol. 2014;32:223-6.

23. Wiśniewski JR, Rakus D. Multi-enzyme digestion FASP and the "Total Protein Approach"-based absolute quantification of the Escherichia coli proteome. J Proteomics. 2014;109:322-31.

24. Wiśniewski JR, Ostasiewicz P, Duś K, Zielińska DF, Gnad F, Mann M. Extensive quantitative remodeling of the proteome between normal colon tissue and adenocarcinoma. Mol Syst Biol. 2012;8:611.

25. Herring JM, McMichael MA, Smith SA. Microparticles in health and disease J Vet Intern Med. 2013:27:1020-33.

26. Bucciarelli P, Martinelli I, Artoni A, Passamonti SM, Previtali E, Merati G, et al. Circulating microparticles and risk of venous thromboembolism. Thromb Res. 2012;129:591-7.

27. Niccolai E, Emmi G, Squatrito D, Silvestri E, Emmi L, Amedei A, et al. Microparticles: bridging the gap between autoimmunity and thrombosis. Semin Thromb Hemost. 2015:41:413-22.

28. Campello E, Spiezia L, Radu CM, Gavasso S, Zerbinati P, Woodhams B, et al Circulating microparticles in carriers of prothrombin G20210A mutation. Thromb Haemost. 2014;112:432-7.

29. Campello E, Spiezia L, Radu CM, Bulato C, Gavasso S, Tormene D, et al. Circulating microparticles and the risk of thrombosis in inherited deficiencies of antithrombin, protein C and protein S. Thromb Haemost. 2016:115:81-8

\section{Submit your next manuscript to BioMed Central and we will help you at every step:}

- We accept pre-submission inquiries

- Our selector tool helps you to find the most relevant journal

- We provide round the clock customer support

- Convenient online submission

- Thorough peer review

- Inclusion in PubMed and all major indexing services

- Maximum visibility for your research

Submit your manuscript at www.biomedcentral com/submit
Ciomed Central 